\title{
Kinesitherapy Intervention in Improving Degenerative Rheumatic Disorders of Hips Coxarthrosis
}

\author{
Elena Moldovan ${ }^{1 *}$, Veronica Mindrescu $^{1}$ \\ ${ }^{1}$ Professor, Ph.D, Department of Motile Performance, University of Transilvania of Brasov, Romania \\ ${ }^{2}$ Lecturer, Ph.D., Department of Motile Performance, University of Transilvania of Brasov, Romania
}

DOI: $10.36348 / \mathrm{sb} .2019 . \mathrm{v} 05 \mathrm{i} 12.011$

| Received: 11.12.2019 | Accepted: 18.12.2019 | Published: 25.12.2019

*Corresponding author: Elena Moldovan

\section{Abstract}

This paper addresses the importance of kinesitherapy in improving coxarthrosis. Coxarthrosis is also known under the names of hip arthrosis and hip osteoarthrosis and it represents a degradation of the hip joints caused by a morphological and functional lack of balance, being the most frequent hip disorder. The aim of this work is to propose a kinesitherapy programme that slows down the evolution of joint injuries, in the presence of a physical therapist, but also a potential use of the respective programme in the situation of the necessity of an intervention through kinesitherapy in the absence of a specialised physical therapist, because in progressive degenerative diseases, patients are obliged to continue their programme at home. Following the development of the experimental kinetic programme, the subjects were evaluated by means of the Lequesne questionnaire for hip arthrosis, the control of active and passive joint mobility; global muscular power was tested, and on the basis of Trendelenburg's sign.

Keywords: Kinesitherapy intervention, rheumatic disorders of hips.

Copyright @ 2019: This is an open-access article distributed under the terms of the Creative Commons Attribution license which permits unrestricted use, distribution, and reproduction in any medium for non-commercial use (NonCommercial, or CC-BY-NC) provided the original author and source are credited.

\section{INTRODUCTION}

Over recent decades, degenerative rheumatisms have become of increased concern in the population and the medical profession. We can state that arthrosis and spondylosis are considered fairly important in rheumatic pathology and represent preoccupations among the population over 40 years old, both sexes being almost equally affected. Although they do not endanger the life of an individual, major symptoms of degenerative rheumatisms are nevertheless among the diseases that preoccupy most people in contemporary society. Coxarthrosis represents a chronic degenerative disorder of hip joints that occurs in very varied aetiologic conditions, but with the same final result, invalidating joint deformation. It is a relatively often encountered disorder, being the most invalidating among arthroses; it can progress spontaneously to infirmity [1]. The causes of occurrence of coxarthrosis vary from one patient to another, age is an important factor, because a considerable period of time is necessary for the tissues to weaken and the articular cartilage to degenerate or be destroyed. Also, excess weight can create conditions conducive to the occurrence of this disorder [2].
Coxarthrosis supposes changes in the cartilage (dystrophy, erosion), changes in the form (by flattening), changes in the structure (cysts and sclerosis). It associates with the formation of osteophytes and a fibrous capsule, but also a quantitative decrease in the synovial liquid, which leads to a decrease in lubrication [3]. All these changes cause profound alterations of the head of the femur and of the cup of the acetabulum, which no longer have an articular capture, for this reason the destruction of the articular cartilage follows and finally, the deterioration of joints with an immediate result as to the two main functions of hip joints: stability and mobility [4]. In the initial period of the disease two important signs occur, namely: pains during walking and a slight limiting of hip movements. Patients may feel pains in the morning, when making the first movements, pains that disappear after they have made the respective movements. Initially, a limitation regarding abduction, internal and external rotation occurs. These limitations accentuate after an interval of around one year, when even functional impotence can occur, being caused both by an intense pain and a muscular contracture. In some 
cases, the shortening of a leg may occur, as a result of deformation [5].

A complete clinical examination of the other systems has a determining role in the diagnosis of a rheumatic illness, together with the examination of the locomotive system, thus integrating rheumatic sufferance in the general clinic context [6]. Establishing a early and correct diagnosis as well as appropriate treatment are the main factors on which to a large extent the remission or stabilisation of the progressive processes of the disease depend, thus avoiding complications the premature infirmity of the patient. Coxarthrosis is a degenerative rheumatic disorder with which a patient must learn to live. The development of a kinesitherapy programme is of great help; this must be always included in any therapeutic scheme of arthrosis; the orientation of the programme is made depending on the clinical-anatomical-functional stage of the disease. Appropriately controlled movement is essential for maintaining joint lubrication, slowing down the progressive limitation of the amplitude of joint movements and the preservation of the muscular trophism [7].

\section{EXPERIMENTAL SECTION}

In the experimental research, we started from the premise that the drawing up and carrying out of a complex kinesitherapy programme, including means and principles of kinetic treatment, will contribute to improving coxarthrosis and the functionality of the locomotive system.

The most important task of this paper is to harmonise kinesitherapy programmes with coxarthrosis pathology, the drawing up of programmes being determined by the defining aspects of coxarthrosis according to the prognosis of each subject separately. The research was conducted within practical works for the discipline "Measurement and evaluation in kinesitherapy" in collaboration with students specialising in "Kinesitherapy and special motricity" within the Faculty of Physical Education and Mountain Sports, Transilvania University of Brasov. The research sample comprised 100 subjects, from which four patients were selected for the experiment (five females and three male, aged between 50 and 69 years old) each subject having primitive bilateral coxarthrosis as a base diagnosis.

\section{The subjects presented different types of clinical signs of coxarthrosis:}

- Pain with a different character and intensity;

- Limitation of the amplitude of movements;

- Hypotrophy of the muscles stabilising the hip;

- Walking disorders with a different severity.

Coxarthrosis was associated with high blood pressure and circulatory problems in five cases, and in three patient, obesity was also present. The subjects attended kinetic programmes three times a week with a duration of 30 minutes per kinetic session.

The research comprised an initial evaluation, a kinetic programme carried out at the hospital, and a final evaluation. After recording articular and muscular values obtained at the initial evaluation, kinetic programmes were drawn up according to the following objectives:

- An increase of articular stability through improving the force of the muscles stabilising the hip and quadriceps

- Improving active mobility of hip joint to prevent ankylosis and ensuring functional angles for walking and daily activities

- Improving movement coordination

- From all these, an improvement in walking results

In developing these recovery programmes, we took into account the medical data recorded in the hospital admission files and discharge summaries of patients, the prescribed treatments, both those based on medicine and those based on physical exercise. Also, in creating the kinesitherapy programmes, we enumerated the physical exercises during the hospitalisation and some supplementary exercises that we considered would be of use in the recovery from coxarthrosis. All kinesitherapy exercises were done according to the principle of no-pain; when pain occurs, the interruption of exercise was necessary.

The programme comprised: passive mobilisations, within these exercises, fighting muscular contractures was attempted by means of stretching techniques; active-passive mobilisations; exercises of hanging-traction with the aid of pulleys were mainly recommended; hydrokinesitherapy, a multitude of exercises were done in the water: flexions - extensions, abductions-adductions; free active mobilisations: they were the most used for the recovery of joint stiffness [810].

a. Training the flexion, from orthostatism, with the hands fixed against the rib stall, squats are done, from quadrupedy, the hip flexes by inclining the trunk forward towards the floor;

b. Training the extension: ventral decubitus, extensions from the hip are done; supine position, the hands against the rib stall, liftings of the trunk, the heels remaining on the floor.

c. Training the abduction: from orthostatism, lateral lunges are done; from laterally hanging onto the rib stall, the healthy hand and leg leaning against the bars of the rib stall, the abduction of the affected hand and leg is performed; and

d. Training the adduction: supine position, crossings of the legs. 
- Facilitating exercises: the hold-relax technique was used. A contraction of the muscle is executed to the level of painful resistance, followed by a relaxation.

- Pedalling exercises: used also for muscle toning.

- Occupational therapy: aims at prolonging the kinesitherapy exercises for articular mobilisation, using a series of complex activities.

Within the kinetic programme, for ensuring muscle toning, the main groups of muscles of the coxofemoral joint were used:

- The toning of the abductors of the hip is the main objective for enduring unipedal stability. Trendelenburg's sign is due to the insufficiency of abductors. The main abductor is the middle buttock. The exercises for toning this muscle will be done from counterlateral decubitus. The abduction will be done against resistance, isometry being thus performed, or with the help of some weights placed on the inferior third of the calf

- The toning of the lateral rotator group. The toning of these muscles will be performed by isometric exercises. An example of an exercise is: the patient in supine position, the calves hanging over the edge of the bed. External rotation of the hip is done by placing one calf over the other calf. The physical therapist applies resistance on the interior edge of the calf and a counter-resistance on the external side of the knee;

- The toning of the gluteus maximus: from ventral decubitus, the flexed knee at 90 degrees, extensions of the thigh are executed with resistance;

- The toning of the quadriceps, hamstring muscles;

- The toning of the adductors, with a role in bipedal leaning; and

- The toning of the flexors: sitting down, with a flexed knee at 90 degrees, the thigh is flexed against resistance.

Another important technique in the recovery of the mobility of the hip is represented by stretching. This supposes the stretch of the shortened soft tissue and maintaining in this position for a period of time. This stretching of the soft tissue is a passive one, with a duration of approximately 30 minutes. At the moment of performing the stretching, great attention must be given to the speed of execution. Also, in the case of a prolonged rest in bed as well as of ageing, the resistance of the connective tissue is weaker, which implies a need of greater attention to the persons found in these cases. [11]
As indications of executing stretching, we enumerate:

- The execution of some relaxation techniques before stretching;

- The position in which the patient will be during the entire execution of the stretching has to be comfortable and stable;

- The stretching on two muscular groups simultaneously will not be executed; and

- If within two hours of performing the stretching, pain occurs, it is a sign that it was executed with too high an intensity.

Massage has an important role in toning muscles and stimulating blood flow in the soft tissues around a joint. To obtain a painkiller effect, certain ointments based on non-steroidal anti-inflammatories are also used for the massage. The patient will be in ventral decubitus and it starts with a massage on the buttocks and the thigh, then we shall pass onto the muscles of coxofemoral joints. Vibration and tapping schemes are especially used, being known to stimulate the local metabolism and the profound connective tissue [8].

The kinetic programme performed at home was designed on the basis of the exercises executed by the subjects at the hospital, completed with simple active exercises to be executed by the subjects without the supervision of the physical therapist. The same programme was applied with identical exercises for the most, for each patient, but we offered attention to the subjects who needed a programme with individualised exercises together with the others, given the associated diseases and the individual abilities of the patients.

Within the kinetic programme, at the beginning, the discharge positions (decubitus) were used, then the patients would work also from semiloading positions (quadrupedy) or even loading with all the weight of the body (sitting).

As a golden rule, we pursued the principle of no-pain, that is the exercises should not cause pain because it is inadvisable to work on a painful background.

For improving mobility, free active exercises were used and active-self-passive exercises [9]. The toning of the corresponding muscle groups was done by isometric active exercises, with resistance, even by isotonic exercises combined with isometric ones.

Then, we designed a kinetic programme by which patients continued the kinetic programme at home, according to the following objectives:

- Maintaining the muscular force and improvement compared to the level obtained in the hospital; 
- Maintaining articular mobility gained in the hospital to prevent the installation of some grave limitations of mobility that would lead to functional impotence or even articular ankylosis; and

- Therefore, the prevention of the worsening of walking troubles.

The kinetic programme recommended to the subjects for performing at home comprised the following elements $[10,11]$ :

\section{Re-education of the flexion:}

The techniques and methods of increasing articular mobility, used in this case, are:

- Postures

- Passive mobilisations

- Active movements

- Facilitating methods

Postures: The patient in a ventral decubitus, with a pillow under the abdomen, and one at the level of the forehead.

The patient, in supine position, without a pillow under the head, the hands near the body, knees flexed.

The patient, in orthostatism, leaning on the healthy leg, and with the affected leg lifted on a chair (not so high as to force the joint). The height of the chair will be regulated depending on the capacity of the patient to perform the flexion.

Exercise 2: From orthostatism, standing on tiptoes and returning to the initial position. Execution in two series with eight repetitions for each.

Exercise 3: from quadrupedy, looking forward, an alternative flexion of the thigh on the pelvis is performed. They are executed in two series, a series for each leg with six repetitions for each.

\section{Re-education of the extension:}

There are several ways to do this:

a. Postures:

From a supine position, with a pillow under the buttocks, the affected leg is stretched and the healthy leg is flexed as much as the patient can.

b. Passive mobilisations:

As in the case of the flexion, the knee will be always flexed in order to relax the hamstring muscles.

Exercise 1: The patient in ventral decubitus, the physical therapist on the side of the affected leg, fixes with one hand the pelvis on the floor, and with the other hand performs the extensions of the affected leg. Two series of six repetitions each.

c. Self-passive movements:
Exercise 1: The patient in supine position, the healthy leg laying on the floor, the affected leg is flexed on the pelvis, the patient maintaining this position with the help of the hands. Two series of six repetitions each.

d. Active movements:

Exercise 1: From ventral decubitus, the extension of the coxofemoral joint. A series of eight repetitions.

Exercise 2: From quadrupedy, looking forward, the patient performs an alternative extension of legs. Two series of six repetitions each.

\section{Re-education of abduction}

\section{a. Postures}

In supine position, the patient will keep a pillow between the knees.

b. Passive mobilisations

Exercise 1: The patient will sit in supine position, and the physical therapist will fix the pelvis with one hand and with the other he will execute the abduction, performing a hold at the level of the internal intercondylar area of the femur.

c. Self-passive movements

Exercise 1: The patient in a lateral decubitus on the healthy side, the healthy leg hanging on a pulley, and with the help of the physical therapist he will be subjected to traction upwards.

d. Active movements

Exercise 1: From a supine position, the patient performs an alternative abduction of the legs. Two series of six repetitions each.

Exercise 2: From a supine position, the patient performs alternative circumductions of the legs. Two series of six repetitions each.

\section{e. Facilitating methods}

We shall work with the facilitating scheme D1E (extension-abduction-internal rotation). In the slow inversion technique, we shall work on the diagonal D1F.

\section{Re-education of adduction}

a. Postures

Exercise 1: Supine position, the patient with crossed legs, with the knees in extension.

b. Passive mobilisations

Exercise 1: The patient in lateral decubitus, on the affected side, the healthy leg is flexed and leaning against a pillow.

c. Self-passive mobilisations:

Exercise 1: The patient in supine position, the affected leg held in bands to a pulley. The physical therapist will perform the adduction of the affected leg with the help of his hands.

\section{Re-education of rotation}

Exercise 1: From sitting, on a chair, with the thighs and calves together, movements to the left and right are performed. 
Exercise 2: From a ventral decubitus, knees flexed, the movement of the calves to the left and to the right.

\section{RESEARCH METHODS}

The objective clinic examination of the locomotive system was performed by inspection, touching, and ausculation, to which some manoeuvres specific to this system were added. The examination was performed both in supine position and in orthostatism. The subject being in supine position, the examination is done centripetally in the following order: hands, elbows, shoulders, skull, face, and temporomandibular joints. Then, with the subject sitting, the cervical and dorsal spine, the sacral, and coccyx were examined. For certain manoeuvres, ventral decubitus is recommended. The objective examination of the leg is performed centrifugally: we start with the joint hip, then the knee, the ankle, and the leg. The examination is performed both in supine position and ventral decubitus. In the next stage, we move onto the examination of the patient in orthostatism and during walking, when changes in the legs and spine can be highlighted [11].

The evaluation of the subjects consisted of:

- Lequesne questionnaire for hip arthrosis;

- The control of articular and passive articular mobility;

- $\quad$ Testing global muscular force; and
- Testing unipedalism on the basis of Trendelenburg's sign [13].

Regarding the evaluation of patients for the articular assessment, the following movements were measured with the help of a goniometer: movements in a sagittal plane and frontal axis (flexion and extension of the thigh on the trunk); movements in a frontal plane and sagittal axis (abduction and addcution of the leg); and movements in a transverse plane and vertical axis (external and internal rotation).

\section{RESULTS AND DISCUSSION}

Of the group of 100 subjects, eight subjects accepted being monitored as subjects for students who perform practical studies, both over the entire period of hospitalisation and after discharge at home. To check to what extent the functional abilities of a patient were affected, we used a questionnaire to calculate the algofunctional index Lequesne, which showed us how much the patient was affected [12]. This questionnaire was applied subsequently to hospital admission, before the patient effectively began specialised treatment. According to the Lequesne index, the functional abilities of the patient were affected in proportion by less than half, which can be a favourable thing in the recovery process. The lower the affectation degree of a function is, the greater the recovery chances are and vice versa, if the affectation degree of one of the functions is high, the chances of recovery diminish.

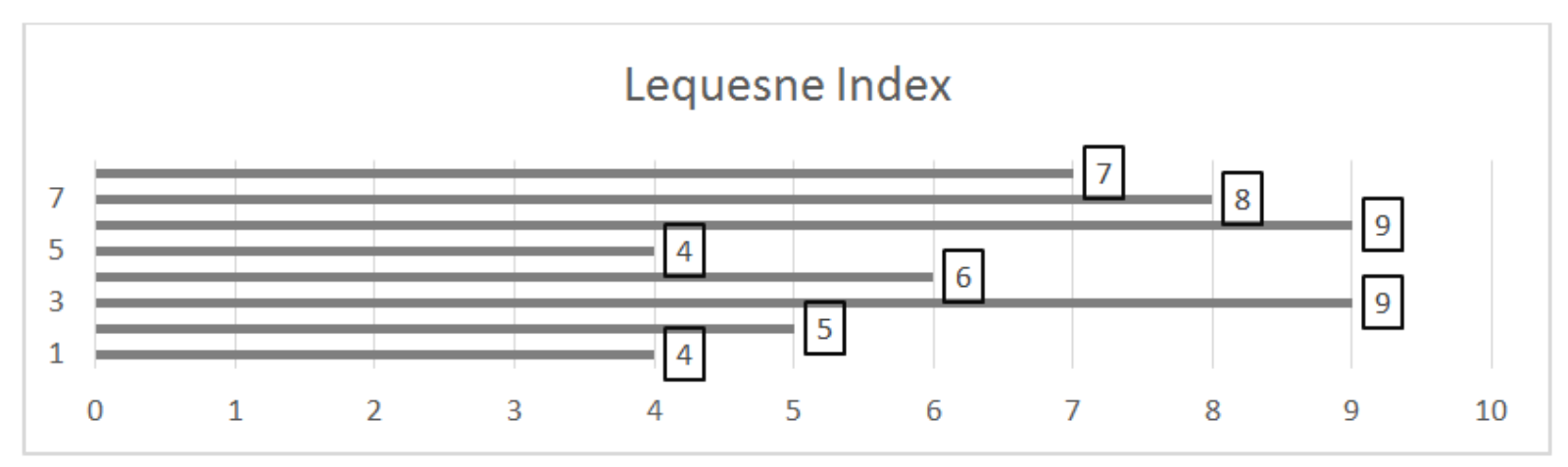

Fig-1: The score obtained by subjects after filling in the Lequesne questionnaire for hip arthrosis

The scale of the Lequesne index is between 024. The total accumulated by subjects is presented in Figure-1. We note that out of the eight subjects, four two subjects have a moderate degree of functional abilities and four subjects have a severe degree, which makes the recovery programme more difficult and at the same time, there is a greater possibility that after a short while the symptoms re-occur or get worse. 
Elena Moldovan \& Veronica Mindrescu., Sch Bull, Dec 2019; 5(12): 767-774

Table-1: Presentation of the values of articular assessment of the hip - Initial evaluation

\begin{tabular}{|c|c|c|c|c|c|c|c|c|c|c|c|c|}
\hline \multirow[t]{2}{*}{ Patient } & \multicolumn{2}{|c|}{$\begin{array}{l}\text { Flexion } \\
\text { (With a flexed } \\
\text { knee) }\end{array}$} & \multicolumn{2}{|c|}{ Extension } & \multicolumn{2}{|c|}{ Abduction } & \multicolumn{2}{|c|}{ Adduction } & \multicolumn{2}{|c|}{$\begin{array}{c}\text { External } \\
\text { rotation }\end{array}$} & \multicolumn{2}{|c|}{$\begin{array}{c}\text { Internal } \\
\text { rotation }\end{array}$} \\
\hline & right & left & right & left & right & left & $\begin{array}{l}\text { rig } \\
\text { ht }\end{array}$ & left & right & left & right & left \\
\hline 1. & 80 & 85 & 3 & 3 & 16 & 20 & 15 & 15 & 0 & 0 & 2 & 3 \\
\hline 2 & 103 & 105 & 8 & 10 & 25 & 30 & 15 & 15 & 8 & 10 & 2 & 5 \\
\hline 3 & 90 & 90 & 5 & 5 & 18 & 20 & 15 & 15 & 15 & 15 & 1 & 3 \\
\hline 4 & 100 & 100 & 10 & 10 & 25 & 20 & 15 & 12 & 25 & 20 & 5 & 3 \\
\hline 5 & 100 & 100 & 13 & 15 & 30 & 30 & 18 & 22 & 30 & 30 & 20 & 25 \\
\hline 6 & 90 & 95 & 5 & 8 & 25 & 25 & 13 & 15 & 8 & 13 & 1 & 1 \\
\hline 7 & 80 & 80 & 2 & 2 & 8 & 8 & 0 & 0 & 5 & 5 & 1 & 1 \\
\hline 8 & 100 & 100 & 10 & 10 & 25 & 20 & 20 & 20 & 12 & 10 & 8 & 8 \\
\hline Average & 92,88 & 94,38 & 7 & 7,88 & 21,5 & 21,63 & 13,88 & 14,25 & 12,88 & 12,88 & 5 & 6,13 \\
\hline $\begin{array}{l}\text { Normal } \\
\text { value }\end{array}$ & \multicolumn{2}{|l|}{120} & \multicolumn{2}{|l|}{25} & \multicolumn{2}{|l|}{60} & \multicolumn{2}{|l|}{30} & \multicolumn{2}{|l|}{45} & \multicolumn{2}{|l|}{40} \\
\hline
\end{tabular}

Table-2: Presentation of the values of articular assessment of the hip - Final evaluation

\begin{tabular}{|c|c|c|c|c|c|c|c|c|c|c|c|c|}
\hline \multirow[t]{2}{*}{ Patient } & \multicolumn{2}{|c|}{$\begin{array}{l}\text { Flexion } \\
\text { (With a flexed } \\
\text { knee) }\end{array}$} & \multicolumn{2}{|c|}{ Extension } & \multicolumn{2}{|c|}{ Abduction } & \multicolumn{2}{|c|}{ Adduction } & \multicolumn{2}{|c|}{$\begin{array}{l}\text { External } \\
\text { rotation }\end{array}$} & \multicolumn{2}{|c|}{$\begin{array}{l}\text { Internal } \\
\text { rotation }\end{array}$} \\
\hline & right & left & right & left & right & left & right & left & right & left & right & left \\
\hline 1. & 78 & 82 & 2 & 2 & 16 & 18 & 20 & 20 & 0 & 0 & 0 & 0 \\
\hline 2 & 105 & 108 & 6 & 8 & 25 & 30 & 20 & 20 & 6 & 10 & 3 & 5 \\
\hline 3 & 90 & 90 & 5 & 6 & 20 & 20 & 20 & 20 & 16 & 16 & 2 & 0 \\
\hline 4 & 103 & 104 & 10 & 10 & 25 & 23 & 16 & 13 & 24 & 20 & 5 & 4 \\
\hline 5 & 113 & 113 & 16 & 19 & 40 & 40 & 25 & 27 & 35 & 35 & 26 & 28 \\
\hline 6 & 100 & 103 & 10 & 14 & 33 & 34 & 18 & 20 & 15 & 17 & 2 & 2 \\
\hline 7 & 90 & 90 & 6 & 5 & 13 & 13 & 5 & 5 & 9 & 8 & 3 & 3 \\
\hline 8 & 115 & 115 & 17 & 17 & 32 & 30 & 25 & 25 & 18 & 18 & 12 & 12 \\
\hline Average & 99,25 & 100,63 & 9 & 10,13 & 25,5 & 26 & 18,63 & 18,75 & 15,38 & 15,5 & 6,63 & 6,75 \\
\hline $\begin{array}{l}\text { Normal } \\
\text { value }\end{array}$ & \multicolumn{2}{|l|}{120} & \multicolumn{2}{|l|}{25} & \multicolumn{2}{|l|}{60} & \multicolumn{2}{|l|}{30} & \multicolumn{2}{|l|}{45} & \multicolumn{2}{|l|}{40} \\
\hline
\end{tabular}

Table-3: Presentation of the evolution of the values of global articular amplitude of the hip in the patients under

\begin{tabular}{|l|l|l|l|l|l|l|l|}
\hline Patient & $\begin{array}{l}\text { Initial } \\
\text { evaluation }\end{array}$ & $\begin{array}{l}\text { Intermediary } \\
\text { evaluation }\end{array}$ & Difference & $\begin{array}{l}\text { Progress } \\
\%\end{array}$ & $\begin{array}{l}\text { Final } \\
\text { evaluation }\end{array}$ & $\begin{array}{l}\text { Difference } \\
\text { between } \\
\text { intermediary } \\
\text { and } \\
\text { evaluation }\end{array}$ & $\begin{array}{l}\text { Progress } \\
\text { final }\end{array}$ \\
\hline 1. & & & & & -33 & $-12,17 \%$ \\
\hline 2. & 336 & 390 & 54 & $16,07 \%$ & 346 & -44 & $-11,28 \%$ \\
\hline 3. & 288 & 346 & 58 & $20,13 \%$ & 305 & -41 & $-11.84 \%$ \\
\hline 4. & 345 & 406 & 61 & $17,68 \%$ & 357 & -49 & $-12,06 \%$ \\
\hline 5. & 433 & 499 & 66 & $15,24 \%$ & 517 & 18 & $3,6 \%$ \\
\hline 6. & 297 & 349 & 52 & $17,5 \%$ & 368 & 19 & $5,44 \%$ \\
\hline 7. & 186 & 234 & 48 & $25,8 \%$ & 250 & 16 & $6,83 \%$ \\
\hline 8. & 343 & 410 & 67 & $19,53 \%$ & 436 & 26 & $6,34 \%$ \\
\hline
\end{tabular}

In Table-3, we can find the sum of the values of articular amplitudes (expressed in degrees) of the hip (Flexion + Extension + Abduction + Adduction + Internal rotation + External rotation) for the three evaluations.

The analysis of the results of the values of the articular assessment of the coxofemoral joint.
The main objective of this research was the rendering of some particular aspects and the highlighting of the general tendency of the evolution of the disease. 
As we can note in the graphs illustrated above, most patients have a slow evolution. On the basis of the parameters highlighted above, a comparative clinical evaluation of the patients was conducted. Before and after the kinesitherapy programme, we followed the highlighting of the real efficiency of the complex recovery programme in the studied pathology, respectively in the primitive coxarthrosis. The first parameter studied in the research was an objective parameter, namely the articular mobility. Although the recovery of the stability of the hip by muscle toning is the main objective in coxarthrosis, improving coxofemoral mobility is desired as the first condition for the recovery of the function of the hip of the patient. In this study, the aim was to limit or delay the occurrence of joint stiffness and to gain as many degrees of movement as possible. In order, coxarthrosis interests especially the movement of flexion-extension, then the abduction, the adduction and external and internal rotation, to highlight the efficiency of the proposed kinesitherapy programme, at the level of the movements with the highest disfunction.

Table-4: Presentation of the evolution of the values of global muscular testing of the hip in the patients under study

\begin{tabular}{|l|l|l|l|l|l|l|l|}
\hline Patient & $\begin{array}{l}\text { Initial } \\
\text { evaluation } \\
\text { (scor) }\end{array}$ & $\begin{array}{l}\text { Intermediary } \\
\text { evaluation } \\
\text { (scor) }\end{array}$ & Difference & $\begin{array}{l}\text { Progress } \\
\%\end{array}$ & $\begin{array}{l}\text { Final } \\
\text { evaluation }\end{array}$ & $\begin{array}{l}\text { Difference between } \\
\text { intermediary } \\
\text { final evaluation }\end{array}$ & $\begin{array}{l}\text { Progress } \\
\text { \% }\end{array}$ \\
\hline 1. & 9 & 14 & $\mathbf{5}$ & $\mathbf{5 5 , 5 5 \%}$ & 9 & $\mathbf{- 5}$ & $\mathbf{- 3 5 , 7 1 \%}$ \\
\hline 2. & 11 & 16 & $\mathbf{5}$ & $\mathbf{4 5 , 4 5 \%}$ & 10 & $\mathbf{- 6}$ & $\mathbf{- 3 7 , 5 \%}$ \\
\hline 3. & 10 & 15 & $\mathbf{5}$ & $\mathbf{5 0 \%}$ & 9 & $\mathbf{- 6}$ & $\mathbf{- 4 0 \%}$ \\
\hline 4. & 13 & 17 & $\mathbf{4}$ & $\mathbf{3 0 , 7 6 \%}$ & 13 & $\mathbf{- 4}$ & $\mathbf{- 2 3 , 5 2 \%}$ \\
\hline 5. & 15 & 18 & $\mathbf{3}$ & $\mathbf{2 0 \%}$ & 19 & $\mathbf{1}$ & $\mathbf{5 , 5 5 \%}$ \\
\hline 6. & 12 & 16 & $\mathbf{4}$ & $\mathbf{3 3 , 3 3 \%}$ & 17 & $\mathbf{1}$ & $\mathbf{6 , 2 5 \%}$ \\
\hline 7. & 11 & 16 & $\mathbf{5}$ & $\mathbf{4 5 , 4 5 \%}$ & 17 & $\mathbf{1}$ & $\mathbf{6 , 2 5 \%}$ \\
\hline 8. & 8 & 13 & $\mathbf{5}$ & $\mathbf{6 2 , 5 \%}$ & 15 & $\mathbf{2}$ & $\mathbf{1 5 , 3 8 \%}$ \\
\hline
\end{tabular}

From the point of view of the strength of the key muscles (Table-4), they showed a progress between $20 \%-62.5 \%$. At the final evaluation we found the clear difference between initial and final testing. Thus based on the results, we can say that the patients maintained the values gained during the recovery by kinetic therapy or even improved it (the progression on the amplitude of the movements of the hip joint was $5.2 \%$ on average, and the progression of the strength of the tested muscles was $10.4 \%$ on average) due to the continuation of kinetic exercises and at home.

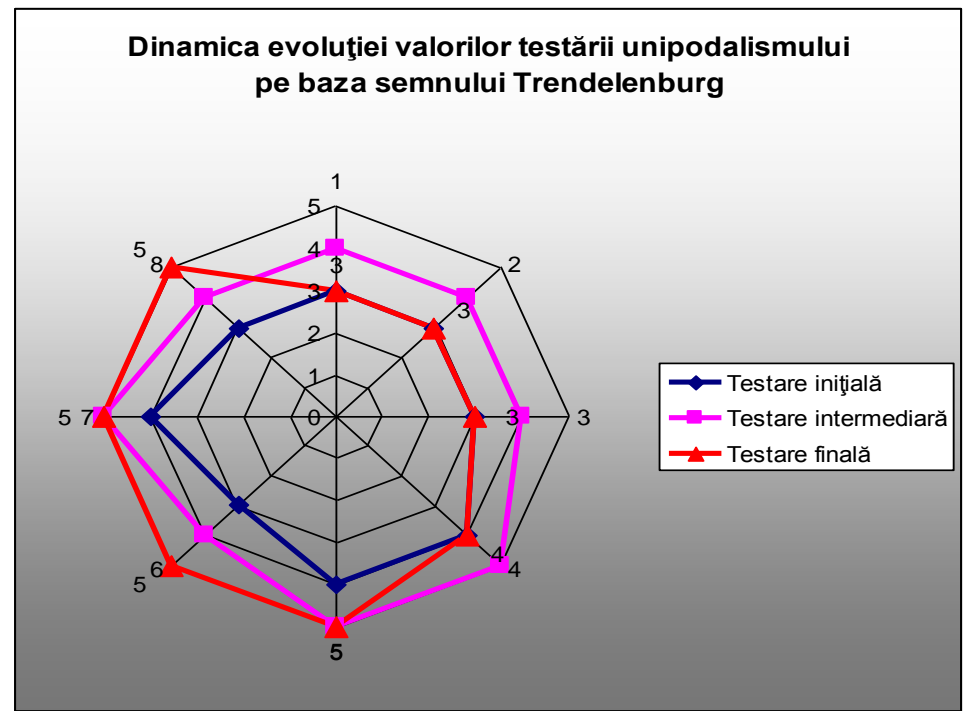

Fig-2: Representation of the evolution of values of the testing of unipedalism on the basis of Trendelenburg's sign

For evaluating walking, we used the following test based on Trendelenburg's sign:

- Patient in orthostatism, front-superior iliac crests are marked

- The patient is asked to pass to unipedal leaning
- the angle between the horizontal and the line that unites the two front-superior iliac crests

We used this test because the unipedal leaning is an essential stage of walking.

Rating:

- angle between $25-30^{\circ}=0$ points 
- angle between $20-25^{\circ}=1$ point

- angle between $15-20^{\circ}=2$ points

- angle between $10-15^{\circ}=3$ points

- angle between $5-10^{\circ}=4$ points

- angle between $0-5^{\circ}=5$ points

This parameter had an ascending evolution for six subjects, a single subject had a descending evolution at the final testing and for one subject, the tested values recorded a stagantion as compared to the intermediary testing.

Therefore, we note a good evolution of this parameter, especially in the case of patients who are not in a final stage, seven of them being between the limits close to normal, accumulating five points and a patient presenting a slight limp, walking being possible without a stick.

\section{CONCLUSION}

Thus, on the basis of the results, we can state that patients maintained the values gained during recovery by kinesitherapy or they even improved them (the progress regarding the amplitude of movements from hip joint being $5.2 \%$ on average, and the progress of the force of the tested muscles was $10.4 \%$ on average) due to the continuation of the kinetic exercises at home. The patients' improvement is not that spectacular in percent, but in primitive coxarthrosis, maintaining existing values is a challenge that can lead to slowing down, and even preventing, the development of the disease.

The progress done presents much higher percent that show that the continuation of the kinetic programme facilitates the speed of illness improvement.The improvement of patients is not that spectacular in percentage terms, but in the primitive coxarthrosis, the maintaining of the existing values is a challenge that can lead to slowing down and stopping the evolution of the disease to advanced stages.

The progress made presents percentages much higher that show us that the continuation of the kinetic programme facilitates the improving of coxarthrosis, preventing its worsening.

\section{REFERENCES}

1. Antonescu, D. (2010). Patologia aparatului locomotor vol 2, Editura Bucureşti, 301-303.

2. Susteanu, Ș. (1999). Bolile aparatului locomotor, Editura Medicală, București, 45.

3. Sbenghe, T. (1987). Kinetologie profilactică,terapeutică şi recuperare, Editura Medicală, Bucureşti.

4. Popescu, E., Ionescu, R., Compediu de reumatologie,Editura Tehnica 1998, Bucureşti, pagina 116

5. Papilian, V. (2003). Anatomia oumului-aparatul locomotor vol 1, Editura Bic All București, 68,130

6. Sabin, I. (2000). Masajul pentru toți, Editura Coressi 2000, București, 123-124.

7. Susteanu, S. (1999). Bolile aparatului locomotor, Editura Medicală, București, 45.

8. Constantin, V. (1989). Exerciţiile fizice $\hat{\imath}$ tratamentul reumatismului articular, Editura SportTurism, București, 30-31.

9. Sidenco, E. L. (1999). Bilanț articular și muscular, Editura APP, București, 135-136.

10. Constantin, V. (1989) , Exerciţiile fizice $\hat{\imath}$ tratamentul reumatismului articular, Editura SportTurism, Bucureşti, 30-31

11. Sabin, I. (2000). Masajul pentru toți, Editura Coressi 2000, București, 123-124.

12. Lequesne, M. (1997). The algofunctional indices for hip and knee osteoarthritis. Journal Rheumatol;24:779-781.

13. Hardcastle, P. H., \& Nade, S. Y. (1985). The significance of the Trendelenburg test. The British Journal of bone and joint surgery. 67(5):741-746. 